\title{
UMA SOLUÇÃO NÃO CONVENCIONAL PARA O PROBLEMA DE GETTIER
}

\section{A NON-CONVENTIONAL SOLUTION FOR THE PROBLEM OF GETTIER}

Luís Estevinha Rodrigues*

\begin{abstract}
RESUMO - O Problema de Gettier (doravante PG) é um marco na epistemologia contemporânea. Passado meio-século do sismo filosófico causado pelo famoso artigo de Gettier (1963), as réplicas continuam e a discussão em torno do problema reacende-se. Adotando nós, como muitos outros, uma posição optimista face à possibilidade de se encontrar uma saída plausível para o PG, apresentamos neste ensaio uma solução não convencional para ele. Crucialmente, defendemos que a única definição plausível do conhecimento proposicional é a que é dada por uma fórmula "aberta" que contém um marcador de posição ou uma "variável" - no lugar da terceira condição necessária - que toma valores consoante o que é necessário e suficiente para haver sucesso epistêmico em circunstâncias específicas.
\end{abstract}

PALAVRAS-CHAVE - Gettier. Conhecimento. Definição. Análise.

ABSTRACT - The Gettier Problem (henceforth GP) is a milestone in contemporary epistemology. Half a century after the philosophical earthquake caused by the well-known Gettier article (1963), solutions continue to appear and the discussion resurfaces. Because we, like many, choose to adopt an optimistic stance towards the possibility of finding a plausible answer to the GP, in this paper we present an unconventional solution to solve it. Crucially, we argue that the only plausible and non-falsifiable definition of the propositional knowledge is the one given by an "open" formula that contains a placeholder or a "variable" - on the third necessary condition - which takes a value according to which, depending on the circumstances, is necessary and sufficient for epistemic success.

KEYWORDS - Gettier. Knowledge. Definition. Analysis.

* Fellow de pós-doutoramento na Universidade de Lisboa, Centro de Filosofia. Membro do grupo de investigação LanCog. Endereço para correspondência: Faculdade de Letras da Universidade de Lisboa, Alameda da Universidade, 1600-214 Lisboa, Portugal. <Lufiro@ gmail.com $>$.

\begin{tabular}{|l|l|l|l|l|l|}
\hline Veritas & Porto Alegre & v. 57 & n. 2 & maio/ago. 2012 & p. 26-50 \\
\hline
\end{tabular}


L. E. Rodrigues - Uma solução não convencional ...

\section{O PG}

A história em torno do PG é bem conhecida, pelo que nos dispensamos de a detalhar aqui ${ }^{1}$. Crucialmente, Gettier argumentou que alguém, $\mathrm{S}$, pode acreditar justificadamente que $p, p$ ser verdadeira, e ainda assim $\mathrm{S}$ não saber que $p^{2}$. Não sendo uma visão consensual, uma vez que, como veremos adiante, existem algumas vozes dissonantes a propósito do tema, existe uma forte tendência para se aceitar que os casos apresentados no artigo de Gettier falsificam a chamada Definição Tradicional do Conhecimento (DTC), a qual reclama que o conhecimento é crença verdadeira justificada (CVJ). Segundo a referida tendência, os casos Gettier originais revelam que a satisfação das três condições, (i) a crença de S que $p$, (ii) a verdade de $p$, e (iii) a justificação da crença de $\mathrm{S}$ que $p$, pode não ser suficiente para $\mathrm{S}$ saber que $p$. O corolário é que a análise do conceito de conhecimento em termos dos conceitos alegadamente mais primitivos e mais claros indicados pelas condições i, ii e iii não pode estar em ordem.

O PG tem duas vertentes. A primeira diz respeito à falsificação da DTC e às razões que a ela conduzem. A segunda diz respeito às respostas e respectivas alternativas que essas respostas apresentam. Lidaremos com a primeira parte do problema nesta seção e deixaremos a segunda para a seção seguinte.

Um exercício que propomos agora ao leitor é imaginar qual seria a sua postura face à DTC, se desconhecesse os contraexemplos a essa definição do conhecimento. Talvez o leitor pensasse que as condições na análise estivessem perfeitamente em ordem, uma vez que elas acomodam bastante bem as nossas intuições acerca do fenômeno do conhecimento. A DTC acomoda, por exemplo, a nossa intuição de que o conhecimento tem de ser uma espécie de convicção fundamentada, ou que só o que é o caso é passível de ser conhecido, ou que há um conjunto de condições necessárias e suficientes para o conhecimento. Ora, se a DTC é tão compatível com algumas das nossas intuições mais básicas a respeito do fenômeno do conhecimento, por que razão estamos (pelo

1 Ver, por exemplo, Chisholm (1966, p. 5; 1989, p. 91 ss), Shope (1983 passim), Dancy (1985, p. 39-53), Steup (2006), Audi (2011, p. 246-265). É um lugar-comum na literatura que a discussão em torno de uma definição do conhecimento e seus problemas remonta a Platão, a quem é frequentemente atribuída a paternidade do projecto de encontrar as condições necessárias e suficientes para alguém ter conhecimento. Aceita-se também geralmente que apesar de ter lançado as bases para discussão, Platão nunca se comprometeu com qualquer definição.

2 Assumimos também que o leitor está familiarizado coma discussão e que sabe que o que PG põe em causa é justamente o conceito de conhecimento proposicional. " $p$ " refere pois uma proposição. 
menos uma considerável maioria) dispostos a aceitar a sua incorreção quando confrontados com os casos-Gettier originais?

Zagzebski (1999, p. 95ss.) alega que a definição de conhecimento deve ser uma definição real (nos moldes sugeridos por Locke), devendo dizer respeito a um só conceito e devendo respeitar os seguintes desideratos teóricos: (1) não ser ad-hoc; (2) não ser negativa; (3) ser breve e precisa; (4) não ser circular (ser informativa); e (5) os conceitos no seu definiens devem ser menos obscuros (opacos) que o conceito no seu definiendum ${ }^{3}$. Ora, supor que DTC respeita todos esses requisitos não parece ferir a maioria dos juízos filosóficos a seu respeito presentes na literatura. Qual é pois o problema? O problema é que é falsa, uma vez que não apresenta as condições suficientes para haver conhecimento. Os casos-Gettier são primeiro que tudo contra-exemplos a essa alegada suficiência.

Se há coisa que meio-século de literatura especializada sobre o PG nos permite é gerar casos-Gettier que nos deixam eliminar algumas das complicações próprias dos contra-exemplos originais de Gettier ${ }^{4}$. Suponha-se, pois, que ao passear pela Casa Branca, em Washington, Dilma Rousseff vê uma projeção holográfica de Barack Obama tão perfeita e tão impossível de distinguir - usando apenas a visão - de um ser humano que lhe parece ser o próprio Obama (de carne e osso) que se encontra ali, em frente a si. Tendo essa evidência (perceptual), Dilma passa a acreditar justificadamente que Obama está à sua frente. Ora, sem que Dilma possua qualquer evidência nesse sentido, Obama está realmente à sua frente, mas atrás do holograma (falando com Hillary Clinton, podemos supor), só que Dilma não o vê, pois o próprio holograma a impede de vê-lo. Assim, Dilma tem uma CVJ que Obama está à sua frente, mas não o sabe. Por conseguinte, o conhecimento não pode ser CVJ, pois há pelo menos um caso de CVJ que não é um caso de conhecimento.

\section{Uma tipologia das respostas ao PG}

Sendo o PG, estritamente falando, o problema da falsificação da DTC, a sua envolvência estende-se para muito além desse tema. Em sentido lato, é usual usar-se a expressão para se referir toda a discussão subsequente $^{5}$. O debate em torno de uma solução é extenso e não

3 Compare-se com Gupta (2009).

4 Zagzebski (1999, p. 101) fornece uma fórmula estrutural para gerar casos-Gettier.

5 O PG também é por vezes designado por Problema da Quarta Condição, o que é a nosso ver um pouco incorrecto, uma vez que, como veremos adiante, algumas respostas não exigem quatro condições necessárias e suficientes, apenas três, sendo até que algumas das respostas mais audazes apenas preconizam duas. 
podemos fazer-lhe justiça aqui. Mas, podemos apresentar uma tipologia simplificada das várias respostas, discutindo-as.

A nossa tipologia é composta por três níveis. No primeiro nível, separamos as respostas em negativas ou positivas, conforme demitem ou não o problema. No segundo nível, dispomos as diversas hipóteses de solução no que respeita a respostas positivas. O terceiro nível se refere às duas hipóteses positivas mais seguidas, das quais apresentaremos amostras.

No que respeita às respostas negativas, Williamson (2000), por exemplo, alegou que qualquer tentativa de análise falhará, uma vez que qualquer análise ou será falsa, por não fornecer as condições necessárias e suficientes, ou será circularmente viciosa - o analisandum estará inserido no analisans e este falhará em ser informativo -, além de que a amostra de falhanços em fornecer uma tal análise é suficientemente reveladora da inutilidade do projeto de análise do conceito de conhecimento ${ }^{6}$. Juntamente com Lycan (2006), pensamos que demitir o problema negativamente deixa por explicar, por exemplo, por que razão se aceita que muitas instâncias de CVJ são conhecimento enquanto outras não. A demissão negativa do problema não é pois, para nós, uma solução interessante.

Passemos às respostas positivas. A primeira $(\psi)$ passa por demitir a força dos casos Gettier, recusando o seu alcance sob vários pretextos (Pailthorp, 1969). Quem adopta essa posição defende em regra que a DTC está em ordem. A segunda $(\phi)$ passa por negar a necessidade da condição de justificação ou de quaisquer outras condições que não sejam a crença de $\mathrm{S}$ que $p$ e a verdade dessa crença (Sartwell, 1991). Quem adopta essa posição defende que o conhecimento é somente crença verdadeira. A terceira $(\mu)$ passa por alterar o conceito de conhecimento de modo a acomodar os casos Gettier (Hetherington, 1999) ou apontar falhas nos contra-exemplos que façam pender a balança para o lado da DTC (Weatherson, 2003). A quarta ( $\lambda$ ) passa por reforçar a DTC, acrescentandolhe uma quarta condição para fortalecer o grau de justificação, tornar essa justificação infalível, etc. A quinta ( $\beta$ ) passa por substituir a condição de justificação por outra ou outras mais eficazes que permitam evitar casos Gettier ou casos mais sofisticados.

Antes de prosseguir para a nossa própria resposta $(\alpha)$, há que vistoriar essas, referindo o que nos leva a optar por não seguir o caminho proposto por cada uma delas.

6 Williamson não é um céptico e submete no mesmo lugar uma definição de conhecimento: o conhecimento é a atitude factiva (um estado mental) mais inclusiva. Explicar esta definição, suas virtudes e problemas não entra nos nossos planos, até porque já o fizemos noutro lugar. Mas sempre vamos dizendo que esta é mais uma análise, no sentido de análise válida que definiremos na última secção. 
Assim, no que respeita a $\psi$, cuja plausibilidade é sobejamente refutada na literatura (cf. Lycan, 2006), cremos que esbarra com a dificuldade de não ser possível ignorar a força dos casos Gettier no que respeita a demonstrar a falibilidade da justificação. É consensualmente aceito que a falibilidade da justificação tem duas vertentes. Podemos ter crenças justificadas falsas, por um lado, e, por outro, podemos ter crenças justificadas que, apesar de verdadeiras, não são conhecimento. Os casos Gettier e similares demonstram suficientemente bem cada uma dessas possibilidades, ou ambas. Para demonstrar que os casos não falsificam a DTC, os críticos dos casos Gettier têm de ser capazes de mostrar que a justificação de baixo grau ou deficiente de outra maneira (já veremos adiante como), chamemos-lhe justificação-Gettier, não implica falibilidade. Mas, não se vê uma forma convincente de o mostrar. Por conseguinte, não podemos seguir essa via.

A resposta $\phi$ arrasta outras complicações. Não as detalharemos aqui, pois já foram sobejamente dissecadas na literatura (Sosa, 2003, p. 103105). Ainda assim apontaremos três razões que, no nosso entender, nos permitem rejeitá-la. A primeira é a de que assumir que o conhecimento é apenas crença verdadeira nos obriga a rejeitar a intuição ancestral de que o conhecimento exige esforço cognitivo (trabalho epistêmico) e fundamentação, uma vez que aquele tipo de crença dispensa a primeira cláusula da maior parte das vezes, enquanto torna a segunda inútil. A segunda razão é a de que, se a perspectiva for verdadeira, força-nos a aceitar que crenças verdadeiras simpliciter (ou palpites sortudos) e crenças fortemente justificadas têm o mesmo valor. Se estivéssemos dispostos a aceitar essa equiparação de valor seria por exemplo (acadêmica e socialmente) equivalente um aluno (ou um cientista, ou um governante, etc.) ter uma crença acidentalmente verdadeira ou uma crença fortemente fundamentada. Mas, não estamos dispostos a aceitar essa equivalência. A nossa recusa assenta naturalmente em uma intuição plausível sobre a real diferença de valor de crenças verdadeiras simpliciter e crenças verdadeiras justificadas. Não obstante, o defensor da posição $B$ pode alegar que ambas contam como conhecimento, havendo apenas uma diferença de grau a separá-las. Mas, isso choca com outra intuição transversal a toda a história da filosofia, a de que um agente só tem conhecimento se exercer corretamente as suas aptidões cognitivas. Ora, muitos casos de crença verdadeira simpliciter não satisfazem essa condição. Suponha-se, por exemplo, que um louco acredita que Obama está atrás de si, não porque tenha qualquer evidência nesse sentido, mas porque está nesse preciso momento a ver Obama discursando (em diferido) na televisão. Por mero acaso, Obama está de fato atrás de si, pois decidiu fazer uma visita nesse dia ao hospício onde está internado 
o louco, estando ele, Obama, na sala onde o louco vê televisão nesse preciso momento, embora essa pessoa esteja voltada de costas para ele. Esse é um caso claro de crença verdadeira simpliciter que ninguém estaria disposto a aceitar como um caso de conhecimento, a não ser talvez pessoas mentalmente desarranjadas (pelos padrões médicos), como o nosso louco. Diga o que disser o proponente de $\phi$, para acomodar a sua intuição de que o louco sabe que Obama está atrás de si terá de acrescentar pelo menos uma cláusula à crença verdadeira do louco, por exemplo, que certos estados mentais, mesmo os que não são sustentados por boas razões, justificam outros. Mas, esse já não será certamente um caso de crença verdadeira simpliciter, mas um caso de crença verdadeira que satisfaz uma terceira condição, o que refuta de imediato a resposta $\phi$.

A resposta $\mu$ é bastante audaz e interessante. Em uma das suas vertentes, o ponto é assumir que os casos Gettier são afinal casos de conhecimento, embora casos em que o agente está muito perto de não saber que $p^{7}$. Esses são segundo Hetherington (1999, p. 571) casos de conhecimento falível ${ }^{8}$. Grosso modo, alguém tem conhecimento falível que $p$ quando as três condições da DTC são satisfeitas, mas uma dessas condições poderia facilmente não ter sido satisfeita. Assim, S sabe falivelmente que $p$ se $\mathrm{S}$ acredita justificadamente que $p$ e $p$ é verdadeira no mundo actual (@), mas em pelo menos um mundo possível próximo de @ uma das três condições necessárias para S saber que $p$ não é satisfeita ${ }^{9}$. Por exemplo, no mundo \próximo de @, S acredita justificadamente que $p$, mas é falso que $p$ (não é satisfeita a condição de verdade); ou no mundo —próximo de @ é verdade que $p$ e S está justificado em acreditar

7 Como o leitor já certamente notou, as respostas $\psi$ e $\mu$ partilham a perspectiva de que os casos Gettier são casos de conhecimento. A diferença nas respostas (e por isso as diferenciámos) consiste na metodologia empregada para o mostrar, sendo que as respostas $\psi$ fazem-no tentando mostrar a força da DTC, enquanto as respostas $\mu$ fazem-no tentando alterar o conceito de conhecimento.

8 Este tipo de conhecimento não poderia ser designado de conhecimento falível, pois o conhecimento não pode exibir essa propriedade da falibilidade, uma vez que se $\mathrm{S}$ sabe que $p$, então $p$. A não ser numa interpretação muito obscura de "conhecimento", segundo a qual falsidades contam como conhecimento, que depois é falsificado (e.g., a principal proposição da teoria geocêntrica de Ptolomeu), o conhecimento é algo infalível. Isto força-nos a admitir, claro, que muito do que aceitamos como conhecimento científico não é afinal conhecimento, uma vez que esse (putativo) conhecimento é revisível e falsificável. Mas isto não é um problema, pois basta supor que muitas proposições de teor científico - pois o método que levou a elas é científico - são absolutamente falsas, quer em $t$, um ponto no tempo em que são tomadas como verdadeiras sendo falsas, quer em $t^{*}$, um ponto no tempo em que a sua falsidade é demonstrada.

9 Assumimos que o leitor tem uma certa familiaridade com a semântica dos mundos possíveis e dispensamos-mos por isso de a explicar. 
que $p$, mas $\mathrm{S}$ não acredita que $p$ (não é satisfeita a condição de crença) ${ }^{10}$; ou ainda, no mundo $\square$ próximo de @, S acredita que $p$ e $p$ é verdadeira, mas a crença de $\mathrm{S}$ que $p$ não está justificada (não é satisfeita a condição de justificação).

Da nossa perspectiva, talvez a principal suspeita que paira sobre essa resposta de Hetherington ao PG tem a ver com a sua pretensão de que os filósofos que interpretam os casos de Gettier como casos em que não há conhecimento têm uma intuição incorreta acerca do assunto. $O$ problema está realmente em perceber-se se os casos Gettier são casos de quase-conhecimento sem serem casos de conhecimento, tal como aceito por uma larga maioria de filósofos, ou se, como sugere Hetherington, são casos de conhecimento que são casos de quase-ignorância. O problema reside, pois, no traçar a fronteira entre conhecimento e ignorância.

Alguns filósofos (por exemplo, Lycan, 2006) demitem liminarmente a hipótese de estarem enganados acerca da condição de ignorância das vítimas com crenças gettierizadas. Turri (2012a) argumenta que um bom critério para diferenciar casos de conhecimento muito falível e casos de ignorância é o fato de não confundirmos casos de conhecimento muito próximos de não o serem, ou seja, casos de conhecimento falível, com casos de conhecimento que, apesar de não serem modalmente seguros (falham em mundos possíveis muito próximos do mundo atual), são tidos como casos claros de conhecimento.

Nós pensamos que, mais do que levantar um problema do lado da compreensão do fenômeno do conhecimento, a resposta de Hetherington traz consequências desagradáveis para a nossa compreensão do que são estados de desconhecimento e estados de ignorância. Se os casos Gettier descrevem casos de conhecimento falível, então a fortiori descrevem casos de conhecimento. Como casos Gettier são casos em que ocorrem falhas epistêmicas de peso, a concepção de Hetherington tem como consequência óbvia que essas falhas não são suficientes para S não saber p. O resultado é que a nossa habitual compreensão do fenômeno da ignorância fica abalada. Se determinadas falhas na evidência disponível para um agente, ou a forma equívoca ou negligente como adquire evidência, ou a coincidência fortuita entre a sua crença e a verdade, só para mencionar algumas falhas, não são de per se suficientes para S não saber que $p$, como determinar então o que é suficiente para S ignorar que $p$ ? E a questão que naturalmente se segue é: se na maior parte das vezes em que avaliamos se alguém tem conhecimento acerca de $p$ consideramos

10 É perfeitamente razoável a ideia de que alguém dispõe de boas razões para acreditar que $p$ sem contudo acreditar que $p$. É a diferença entre justificação situacional e justificação doxástica. No primeiro caso não há crença mas há justificação para a crença, enquanto no segundo caso há justificação para crença e crença (compare-se com Audi 1993, p. 275). 
essas falhas suficientes para alguém ser ignorante a respeito de $p$, por que razão não as iríamos considerar também suficientes para as vítimas de gettierização serem ignorantes a respeito daquilo em que acreditam? Hetherington discordaria certamente dessa avaliação, reafirmando que só haveria ignorância no caso de falhar, no seu sentido modal de "falhar", uma condição necessária da DTC, principalmente a condição de justificação. Mas, claro, ver a falha apenas em termos de justificação é ter um crivo muito estreito para filtrar falhas epistêmicas. Assim que alargamos esse crivo deixa-se de poder evitar a impressão de que certas falhas epistêmicas no modo como a justificação é construída, ou como a crença acerta na verdade, são suficientes para alguém ser ignorante a respeito daquilo em que acredita.

A segunda vertente da resposta $\mu$ remete-nos para ideia de Weatherson (2003) de que as intuições que sustentam os casos-Gettier são duvidosas e falíveis. O ponto geral é o seguinte: se uma teoria $T$ afirma que todos os $F$ são $G$ e um alegado contra-exemplo $C$ a $T$, apoiado na intuição $I$ (ou no conjunto de intuições $I_{1} \ldots I_{n}$ ), parece mostrar que alguns $F$ não são $G$, então (1) ou $I$ está correta e falsifica $T$ (a perspectiva mais aceita no que respeita ao PG) ou então (2) T está em ordem e I é falível e incorreta. Weatherson defende $2 \mathrm{com}$ base em considerações que remetem para a análise semântica (curiosamente também recheada de intuições) de "sabe que...", que não estamos preparados para discutir aqui, e com base em outras considerações de ordem epistemológica. No que respeita a essas últimas, quanto a nós as mais interessantes do ponto de vista do PG, Weatherson considera (p. 8-9) que, tal como muitas outras, a análise do conceito de conhecimento deve satisfazer quatro preceitos ou desideratos teóricos: (a) deve ser imune a contraexemplos; (b) não deve ter (muitas) consequências teóricas indesejáveis; (c) não deve ser estipulativa (ou arbitrária); (d) deve ser simples. Weatherson argumenta que, sendo uma análise, a DTC satisfaz $b, c$ e $d$, mas não $a$. O seu ponto é que a satisfação desses três desideratos teóricos lhe permite aspirar ser correta.

Em primeiro lugar, pensamos que a falha em satisfazer a é fatal para qualquer tentativa de análise que reclame a suficiência do seu analysans, não podendo de todo ser essa falha compensada pela satisfação dos outros desideratos apontados por Weatherson. Em segundo lugar, parecenos que podemos passar a DTC para o outro lado da barricada do ônus da prova da correção das intuições, bastando para tal supor que, sendo a análise suportada por intuições fortes, filosóficas e práticas, a sua defesa pode muito bem transformar-se em um contraexemplo a outras análises igualmente plausíveis do conhecimento que aparentemente também satisfazem os desideratos teóricos sugeridos por Weatherson. 
Como veremos adiante, Unger propõe uma análise do conhecimento que dispensa a condição de justificação. Mas, se for possível divisar casos em que o conhecimento é CVJ, então a análise de Unger será falsa. Mas, agora o defensor dessa análise pode inverter o ônus da prova, apelando para a falibilidade das intuições subjacentes à DTC, usando exatamente os mesmos argumentos que Weatherson usa para tentar invalidar as intuições que se opõem à DTC. A solução que apresentamos no final evita este gênero de conflitos e respectivos aborrecimentos teóricos.

Constituindo o grosso das réplicas ao PG, as respostas dos tipos $\lambda$ e $\beta$ diluem-se em um vasto número de teorias a que não podemos fazer justiça aqui ${ }^{11}$. Ainda assim, a nossa tipologia ficaria severamente truncada se não apresentássemos algumas amostras das respostas respeitantes a cada um dos tipos. É o que faremos na próxima seção.

\section{Respostas de tipo $\lambda$ e de tipo $\beta$}

A teoria da infalibilidade da justificação de Lehrer e Paxson (1969, doravante L\&P) é talvez o exemplar de resposta do tipo $\lambda$ mais conceituado e que mais eco obteve na literatura ${ }^{12}$. A ideia subjacente a essa resposta é a seguinte: os casos Gettier e similares mostram que $\mathrm{S}$ não sabe que $p$ mesmo tendo uma CVJ que $p$, porque nesses casos há uma proposição verdadeira, $q$, que anula a justificação da crença de $\mathbf{S}$ que $p$, tornando-a falível. Assim, S tem conhecimento não-básico que $p$ se, e só se, (i) $p$ é verdadeira, (ii) S acredita que $p$ e (iii) há uma proposição $r$ que justifica completamente $\mathrm{S}$ em acreditar que $p$ e não há qualquer proposição q que anule essa justificação ${ }^{13}$. Uma proposição $q$ invalidará a justificação $r$ que $\mathrm{S}$ tem para acreditar que $p$ se (a) q é verdadeira e (b) a conjunção de $p$ e $q$ não justifica completamente $\mathrm{S}$ em acreditar que $h$.

L\&P notam, no entanto, que essa definição de invalidante da justificação é demasiado forte, uma vez que permite que certas proposições verdadeiras possam ser invalidantes de uma justificação quando não têm alegadamente legitimidade para o serem ${ }^{14}$. L\&P ilustram essa dificuldade

11 De que são exemplo a teoria causal do conhecimento, de Goldman (1967), ou a teoria condicional do conhecimento, de Nozick (1981, p. 172 ss).

12 A literatura mostra múltiplas tentativas na mesma linha, quer dizer, com o mesmo princípio norteador, por exemplo, a de Klein (1971, p. 475).

13 L\&P estão preocupados com o conhecimento proposicional não-básico. A nossa notação difere da deles.

${ }^{14}$ Embora não seja um tópico capital para os fins deste ensaio, importa salientar que a literatura distingue geralmente entre invalidantes (defeaters) e anuladores (overriders). Assim, por exemplo, um invalidante de uma justificação pode vir a anular essa justificação, tornando-se num anulador, caso não haja outros invalidantes que o invalidem e o anulem. 
com um célebre exemplo. Resumindo-o, S vê $(\Sigma)$ Tom a sair da biblioteca com um livro escondido no casaco e passa a acreditar justificadamente, com base em $\Sigma$, que $(\Omega)$ Tom furtou o livro. Contudo, a mãe de Tom, uma mentirosa recorrente, afirma que quem furtou o livro foi o irmão gêmeo de Tom, o que é falso. Mas, considerando a análise acima, a proposição verdadeira ( $($ ) "A mãe de Tom disse que quem roubou o livro foi o seu irmão gêmeo" é, prima facie, um invalidante de $\Sigma$, uma vez que $\Phi$ é verdadeira e a sua conjunção com $\Sigma$ não justifica completamente $\mathrm{S}$ a acreditar que $\Omega$. L\&P alegam, contudo, que $\Phi$ não é realmente um invalidante de $\Sigma$, pois, para o ser, S teria de estar completamente justificado em acreditar que $\Phi$ é falsa ${ }^{15}$. Mas, ele não o está, pois para o estar, pela definição apresentada, não poderia haver qualquer proposição verdadeira que invalidasse a sua justificação para acreditar na falsidade de $\Phi$. Mas, essa proposição existe e é óbvia: " $\Phi$ é verdadeira" ${ }^{16}$. $\Phi$ é, portanto, um putativo invalidante de $\Sigma$. Por isso, $\mathrm{S}$ sabe que $\Omega$.

Talvez a principal objeção movida às teorias que preconizam a ausência de invalidantes ou de anuladores seja a da não necessidade da condição de não existirem invalidantes da justificação (cf. Sosa, 1970, p. 63). Nos casos que pretendem ser contra-exemplos à necessidade da condição, S tem uma crença completamente justificada, por $r$, que $p$, mas há um invalidante $q$ de $r$ - segundo as condições declaradas como necessárias e suficientes pela concepção de L\&P para uma proposição ser um invalidante - que em conjunção com $r$ anula a justificação que $\mathrm{S}$ tem para acreditar que $p$. Contudo, esses casos são casos em que, pelo menos intuitivamente, $\mathrm{S}$ sabe que $p$. É por isso alegado que a análise de L\&P impõe condições desnecessárias para o conhecimento. Lycan et alii (1973) argumentam que o contraexemplo de Sosa não colhe, mas depois defendem que a análise de L\&P acaba por colapsar na DTC, sendo por isso mesmo susceptível de sofrer dos mesmos problemas que essa análise clássica. Outros alegados contraexemplos à suficiência da análise de

${ }^{15}$ L\&P apresentam o também famoso caso Nogot como um paralelo ao caso Grabit. No primeiro há um invalidante para a justificação porque há uma proposição verdadeira em que o agente está completamente justificado em acreditar que é falsa (Nogot não tem um Ford), e que, quando em conjunto com o que justifica a crença desse agente, não o justifica completamente a acreditar que no que acredita. Daí que para L\&P o caso Nogot seja um caso Gettier, um caso de ignorância, pois neste caso há um anulador para justificação, enquanto o caso Grabit é um caso de conhecimento, porque neste último não há um anulador para a justificação do agente.

${ }^{16}$ L\&P introduzem uma condição adicional para dar conta de conjunções que aparentemente se qualificam como invalidantes porque, apesar de verdadeiras, o agente está completamente justificado em acreditar na sua falsidade, uma vez que está completamente justificado em acreditar na falsidade de um dos conjuntos, o qual é no entanto irrelevante para a justificação propriamente dita. Não iremos detalhar o tópico, sendo que ele também não nos parece crucial para o nosso presente ponto. 
L\&P podem ser encontrados em outros lugares e autores. Por exemplo, Zagzebski (1999, p. 102) sugere-nos um caso em que um médico não tem qualquer contraevidência que invalide a sua justificação de que o doente $X$ tem o vírus $y$, mas em que ainda assim $X$ não pode saber que $p$ porque é acidental que a justificação de $X$ para a sua crença de que $p$ garanta adequadamente a verdade dessa sua crença.

Apesar das múltiplas tentativas falhadas (considerando a opinião corrente disponível em vários pontos da literatura especializada) que se seguiram de análise do conhecimento em termos de CVJ $+x$, seria de esperar que esse projecto estivesse por essa altura abandonado, para mais tendo em conta os convincentes argumentos de Williamson contra a possibilidade de ser levado a bom porto. Mas, a julgar por algumas tentativas recentes para apresentar uma definição em termos de CVJ $+x$, o desiderato que motiva respostas do tipo $\lambda$ ainda não está extinto. Por exemplo, Turri (2011) alega que o conhecimento é CVJ, tal que a crença de $\mathrm{S}$ que $p$ não apenas tem origem no exercício das disposições cognitivas de um agente, o que ainda assim segundo o próprio Turri pode permitir casos-Gettier, como é o resultado dessas disposições, manifestando-as ${ }^{17}$.

As definições que assentam na ideia de que o conhecimento é um resultado apropriado do exercício das aptidões cognitivas de um agente parecem lidar mal com casos célebres em que esse exercício tem lugar, mas em que, alegadamente, não há conhecimento. O espectro do famoso caso dos celeiros fachada (Goldman, 1976, p. 772), o qual continua a dividir opiniões e intuições quanto a ser ou não um caso de conhecimento, parece pairar ameaçadoramente sobre qualquer tentativa de analisar o conhecimento em termos de crença verdadeira em virtude de condições de aptidão intelectual e cognitiva ${ }^{18}$. Lycan, Hetherington e outros rejeitam que esses sejam casos de conhecimento, o que os invalidaria como contraexemplos às mencionadas definições. Mas, nós cremos que, apesar de estarem em uma zona bastante cinzenta, a mera possibilidade de serem casos de conhecimento é suficiente para lançar uma dúvida razoável sobre essas definições.

Além disso, é possível encontrar na literatura críticas de outra ordem à análise de Turri. Hetherington (2011) argumenta que a posição de Turri é insustentável, porque espelha uma visão infalibilista do conhecimento, ao passo que o que Gettier tinha em mente era justamente a falibilidade do

17 Uma tentativa que vem na linha de muitas outras, como por exemplo as de Sosa (2007), Greco (2008).

18 Vide Pritchard (2010, Primeira Parte). Famosamente também, Lackey (2007, p. 352) oferece um alegado contra-exemplo à necessidade do referido tipo de condição, o qual assenta num suposto caso de conhecimento por testemunho que não envolve o exercício de capacidades cognitivas por parte do agente. 
conhecimento. Por mais interessantes que estes debates sejam, cremos que eles assentam num equívoco fundamental: a ideia de que há uma única análise do conceito de conhecimento. Adiante iremos argumentar que, assim que esse equívoco se dissolver, as principais polêmicas geradas em torno de si, ou à sua custa, tenderão também a dissolver-se.

As respostas do tipo $\beta$ visam contornar as complicações típicas que acompanham as respostas do tipo $\lambda$, em especial os problemas relacionados com a falibilidade da justificação e ao grau e ao tipo de justificação necessário e suficiente para garantir a verdade da crença, etc. As teorias causais do conhecimento têm um papel proeminente nessa economia de respostas. Elas visam eliminar o defasamento típico, descrito nos casos-Gettier, entre a crença de alguém e o fato descrito pela proposição que é alvo da sua crença. Essas teorias propõem uma ou mais condições que visam eliminar esse defasamento. Recuperemos, por um instante, o caso que divisamos acima, no qual Dilma via um holograma de Obama, embora da posição de Dilma não se pudesse ver o próprio Obama. Segundo o defensor da teoria causal, uma condição necessária para Dilma saber nessas circunstâncias que Obama está à sua frente é a de que a crença de Dilma tenha sido causada pelo fato de Obama estar à sua frente, e não, como no exemplo, causada pelo fato de estar um holograma de Obama à sua frente. A seguinte será, pois, uma condição necessária para alguém saber que $p$ : a crença que $p$ de S está em uma relação causal apropriada com o fato descrito por $p$. Então, sumariamente, para, por exemplo, S saber que Obama é o $44^{\circ}$ presidente dos EUA terá de (i) acreditar que Obama é o $44^{\circ}$ presidente dos EUA, (ii) isso terá de ser o caso e (iii) esse fato é a causa (ou uma das causas) da crença de $\mathrm{S}$ descrita em i (cf. Goldman, 1967, p. 369).

As teorias causais debatem-se, contudo, com alguns problemas sérios, por exemplo, o do conhecimento do futuro, admitindo que existe tal conhecimento, e que parece exigir que a causa (um fato ou evento no futuro) da crença de que $p$ (que se refere ao futuro) seja temporalmente posterior ao seu efeito: essa crença. Ou com o problema do conhecimento de proposições que se referem a fatos não facilmente identificáveis ou confirmáveis, como por exemplo fatos morais ou fatos matemáticos, sendo que ambos dificilmente têm uma contraparte natural, o que torna difícil aferir a real causa das crenças que podem estar na base desses subtipos de conhecimento.

Passemos agora a outro exemplar de resposta $\beta$. Uma das características dos casos-Gettier ou similares é o modo acidental como a crença de alguém acerta na verdade. Algumas das mais salientes respostas do tipo $\beta$ têm como objectivo "suprimir" essa acidentalidade, a qual é aparentemente incompatível com as nossas intuições acerca da natureza 
do conhecimento (cf. Pritchard, 2005 passim). Unger (1968, p. 157-170) oferece-nos uma dessas tentativas, sugerindo que o conhecimento pode ser definido da seguinte forma:

Para qualquer proposição $\mathrm{p}$, alguém sabe que $\mathrm{p}$ se, e só se, não é de modo algum acidental que essa pessoa esteja correcta acerca de ser o caso que p. (ibid., p. 158)

Unger separa a acidentalidade do fato da acidentalidade do vínculo entre crença e fato. É este último tipo de acidentalidade que está em causa e que não pode estar presente nos casos de conhecimento.

A compreensão de que a crença deve ser não acidentalmente verdadeira para ser conhecimento deu origem a diversas tentativas de análise que incluem restrições de não acidentalidade, por vezes também referidas como condições antiacaso epistêmico, tendo recentemente adotado um novo formato: segurança epistêmica da crença. Dispensamonos de entrar no detalhe da discussão acerca das condições de segurança epistêmica definidas com o auxílio da semântica dos mundos possíveis. Basicamente, uma crença é epistemicamente segura se não puder ser facilmente falsa (cf. Sosa, 1999, p. 143). Embora existam restrições adicionais à seguinte definição, uma crença será facilmente falsa caso seja verdadeira no mundo@, mas seja falsa em pelo menos um mundo possível próximo de@.Um mundo possível próximo de @ é apenas um mundo similar ao @, que, não sendo atualizado, poderia ter ocorrido, e esse mundo exibe ligeiras diferenças em relação a @, por exemplo, p é falsa nesse mundo.

As intuições de que o conhecimento não é compatível com o deficiente exercício das habilidades cognitivas de um agente e com a forma acidental como as suas crenças são verdadeiras motivou recentemente o surgimento de conjuntos ecléticos de condições complementares que visam acomodar essas intuições. Tentando conciliar e harmonizar um conjunto de propostas oriundas da chamada epistemologia das virtudes e da literatura que reporta a condições de segurança epistêmica definida em termos modais, Pritchard (2010) submete esse tipo de solução, alegando que a conjunção das duas condições, a (C-antA) condição de antiacidentalidade da crença e a ( $\mathrm{C}$-corE) condição de que esta derive do correcto exercício das capacidades cognitivas de um agente (a qual inclui bastantes restrições e precisões que não trataremos neste lugar), dá conta do que é necessário e suficiente para haver conhecimento.

Não sendo uma resposta direta ao PG, e sendo um esforço louvável de conciliar intuições aparentemente corretas e complementares acerca do conhecimento, a tentativa de Pritchard não é todavia isenta de críticas. 
Carter (2011) ensaia uma dessas críticas. Basicamente, ele alega (ibid., seção 4) que o sucesso da definição de Pritchard depende daquilo que designa por tese da independência das condições, que atribui a Pritchard. A tese reclama que a satisfação de qualquer uma das condições não implica necessariamente a satisfação da outra, daí a necessidade de as duas serem satisfeitas. Carter rejeita, contudo, a referida tese, alegando que a satisfação da C-corE implica a satisfação da C-antA, o que, a ser correto, derruba a pretensão de independência das condições.

Isso termina o nosso breve périplo por algumas das respostas positivas ao $\mathrm{PG}$, o que termina também a nossa tipologia. Na próxima seção, valemo-nos da "fotografia" que tiramos a essa vertente do PG para rejeitar as respostas convencionais, negativas e positivas, submetendo uma alternativa.

\section{Uma solução não convencional para o PG}

Há duas posturas ex ante no que respeita ao PG, a otimista e a pessimista. Comecemos por esta última. Antecipando o locus classicus pessimista de Williamson (2000) a propósito da possibilidade de se encontrar uma análise verdadeira do conceito de conhecimento, Zagzebski (1993) reclama que não é possível apresentar uma análise do conhecimento imune a contraexemplos, uma vez que qualquer análise que deixe espaço para a falibilidade da terceira (quarta, etc.) condição, no sentido em que a sua satisfação deixa em aberto a possibilidade lógica de a crença ser falsa, irá ter como consequência o colapso dessa análise sob o peso de contraexemplos que explorem esse hiato entre crença e verdade (compare-se com Turri, por publicar). Em outro registo, Floridi (2004) argumenta que, se não é possível evitar os contraexemplos à DTC, modificando a condição de justificação ou adicionando uma quarta condição, então a DTC é irreparável em princípio e devemos procurar uma solução alternativa. Acrescente-se a essa argumentação as dificuldades ditadas pelos requisitos para uma boa definição do conhecimento, desideratos (1) a (5) descritos por Zagzebski a que aludimos na Secção 0 , e o historial de tentativas falhadas de solução positiva (logo, otimista) do PG. Considerando essa amálgama de dificuldades, o cenário torna-se bastante turvo para o paladino da atitude otimista. Estaremos pois a esse respeito condenados ao pessimismo? Não nos parece. Cremos que esse pessimismo só tem razão de ser em função de uma perspectiva incorreta acerca da solução adequada para o PG.

Qual é então a solução adequada? Em primeiro lugar, é uma solução que deve romper com as linhas de solução tradicionais, sejam as negativas ou as positivas, uma vez que nenhuma demonstra ser eficaz 
do ponto de vista da explicação. As respostas negativas deixam por explicar as razões por que estamos dispostos a aceitar que algumas análises falsificadas por contraexemplos, como a DTC, dão intuitivamente conta do que é necessário e suficiente para alguém saber que $p$ em determinadas circunstâncias, mas não noutras. As respostas de tipo $\psi$ apresentam explicações implausíveis, pois é implausível que muitos do contraexemplos tipo-Gettier sejam improcedentes. As respostas de tipo $\phi$ apresentam explicações implausíveis porque não dão conta da evidente diferença de valor entre crenças verdadeiras e, por exemplo, crenças verdadeiras justificadas não gettierizadas. As respostas positivas de tipo $\mu$ conflituam com intuições filosóficas enraizadas e muito aceitáveis a propósito da natureza do conhecimento, da ignorância, de contraexemplos e das próprias intuições sobre essas coisas. Por conseguinte, apresentam explicações no mínimo estranhas e inconsistentes com posições sensatas do ponto de vista filosófico. $\mathrm{E}$ as respostas de tipo $\lambda$ e de tipo $\beta$ prestam-se a ser falsificadas no que respeita à necessidade, suficiência, ou ambas, das condições que preconizam. A solução adequada deve, pois, desviar-se dessas linhas de investigação, se possível, descontinuando-as.

Em segundo lugar, a solução adequada deve ser capaz de fazer luz sobre o problema elucidando a verdadeira natureza do conceito de conhecimento, acomodando concomitantemente múltiplas intuições racionais acerca desse conceito e acerca do formato ideal de definição do fenômeno que lhe corresponde.

Esse objetivo exige que façamos uma excursão prévia sobre um conjunto de hipóteses sobre a natureza do conceito de conhecimento. Essas hipóteses são: (HipC1) Não há nenhum conceito de conhecimento, logo, não pode estar disponível uma análise do conceito de conhecimento; (HipC2) Há um único conceito de conhecimento, o qual é susceptível de ser acomodado e circunscrito por uma análise; (HipC3) Há um único conceito de conhecimento, o qual é susceptível de ser acomodado por múltiplas análises; (HipC4) Há múltiplos conceitos de conhecimento, cada qual susceptível de ser analisado isoladamente.

Parece-nos que ninguém está realmente disposto a aceitar a HipC1. Quanto a nós, o ceticismo a ela inerente impede-nos de a aceitar. Já a HipC4 tem por certo seguidores leais, presumivelmente de linhagem wittgensteiniana. Trata-se de uma hipótese prima facie atrativa, mas estamos em crer que ultima facie desinteressante. Se estivesse em ordem, os problemas habituais multiplicar-se-iam - em vez de ter de resolvê-los para um conceito, teríamos de os resolver para muitos. É, pois, fundamentalmente um princípio de parcimônia que nos leva a abdicar dela. Por último, pensamos que, embora pareçam contrárias, a HipC2 e 
a HipC3 não são realmente incompatíveis. Acreditamos até ser possível articular a ideia de um único conceito com uma análise com a ideia de um único conceito com múltiplas análises.

Contra Zabzebski (1993), que pressupõe a impossibilidade de existirem análises verdadeiras do conhecimento, Zagzebski (1999: 99) afirma não haver inconsistência em supor-se que existem múltiplas definições para um único conceito de conhecimento, cada qual satisfazendo um conjunto de desideratos. Claro que, pensamos nós, sendo esse o caso, nenhuma dessas definições pode, isoladamente, apresentar as condições necessárias e suficientes para o conhecimento. Qualquer uma dessas definições será falsificada enquanto análise, no sentido tradicional de análise que remonta à dialética socrática presente nos diálogos platônicos, pois haverá sempre uma parte do espaço conceptual delimitado pelas nossas intuições acerca do conhecimento que não é abrangida pelo espaço conceptual coberto pelo conjunto de condições no analysans de uma qualquer análise. Mais uma vez, a história do PG e problemas derivados é reveladora a esse respeito, pelo que não iremos insistir mais no ponto. Todavia, não pensamos que a HipC3 seja por isso um caso perdido, indo por isso defendê-la de seguida.

A referida hipótese levanta um problema com duas extremidades. De um lado, o problema das propriedades do conceito de conhecimento e, de outro, o problema das múltiplas análises e respectivas propriedades desse conceito. Já iremos ao segundo problema. No que concerne ao primeiro, vimos que a HipC3 reclama que o conceito de conhecimento é o mesmo. Mas, qual é a acepção de "o mesmo" em jogo aqui? Crucialmente, propomos que o conceito a analisar é uno intensionalmente, numericamente o mesmo. Tal não tem, contudo, como consequência que seja extensionalmente rígido. Imagine-se uma bolha que pode esticarse infinitamente e cujo conteúdo substancial é diverso ${ }^{19}$. Essa bolha é numericamente a mesma, independentemente de estar cheia, meio-cheia

19 A cosmologia contemporânea tende a ver o universo (um dos muitos versos num multiverso) como uma bolha infinita em constante expansão e mutabilidade. Ainda considerando essas hipóteses científicas, a referida bolha contém diversas substâncias: vazio (que tem energia e aparentemente massa), cordas que vibram, matéria e energia negras, quanta, micro (protões, electrões, etc.) e macro elementos (moléculas e seres bípedes sem penas). Sem querer abusar da analogia entre espaço físico e conceptual, e da metáfora do 'conteúdo', parece que não há nenhuma boa razão para pensar que o espaço conceptual não é flexível, mudando o seu conteúdo, tal como o espaço físico, literalmente a partir do vazio. A ideia de um espaço conceptual imutável é certamente uma reminiscência da ancestral mas provavelmente desadequada Teoria das Formas platónica. Assim que deixamos de ver os espaços conceptuais (domínios conceptuais) como entidades imutáveis, rígidas, canónicas, passamos a ter menos problemas com o cepticismo, que se vale da dificuldade em preencher esses espaços conceptuais para salientar-se. 
ou vazia. Porém, à medida que se vai enchendo ou esvaziando, altera-se quantitativamente. Defendemos que o conceito de conhecimento exibe o mesmo tipo de rigidez numérica e flexibilidade (elasticidade) extensional. Sendo numericamente o mesmo, o espaço conceptual relativo à noção de conhecimento expande-se (ou contrai-se). Propomos de seguida que essa variação ocorre em função do espaço conceitual gerado e preenchido por diversas análises válidas do referido conceito.

Isso nos remete ao segundo problema, o das múltiplas análises do conceito de conhecimento e respectivas propriedades. Tratemos em primeiro lugar da possibilidade de existirem múltiplas análises para um único conceito de conhecimento (o tema da quantidade, Tqt). Depois iremos ver as suas principais propriedades (os temas do formato (Tf) e da qualidade (Tql) das análises) e o modo como geram e preenchem o espaço conceitual relativo à noção de conhecimento (a questão metaepistemológica, Q-me).

Tqt. Em uma passagem bem conhecida, Stanley (2005, p. 89ss.) sugere que, seja qual for a nossa análise do conhecimento preferida, a ela terá de ser acrescentada uma condição suplementar indicadora do modo como os interesses práticos de um agente condicionam o seu conhecimento de que $p$ em um momento $t$ (em um certo contexto temporal). Esse não é o lugar indicado para discutir a proposta de Stanley, o qual, não querendo oferecer uma análise do conhecimento, está mais interessado em mostrar que a relação entre a evidência de $\mathrm{S}$ de que $p$ e os interesses práticos de $\mathrm{S}$ relativamente a $p$ condiciona o valor de verdade das atribuições de conhecimento (ou de ignorância) a $\mathbf{S}$ quando acredita que $p$. Ora, embora indiretamente, o ponto de Stanley trabalha a favor da HipC3, pois, se ele estiver correto, uma condição necessária adicional acerca de elementos não epistêmicos tem de ser incluída em uma qualquer análise do conhecimento para que essa esteja correta. Todavia, se assim é, que razões teríamos para pensar que não há muitas outras condições necessárias para o conhecimento?

O problema com o desiderato (4) (o da brevidade da análise) é que a sua satisfação exclui automaticamente muitas dessas condições necessárias. Contraexemplos à suficiência das análises curtas exploram o defasamento entre os espaços conceituais preenchidos por essas análises e o espaço conceptual do relativo à noção de conhecimento, destacando precisamente a porção desse último espaço não coberta pelo espaço conceitual circunscrito por essas análises. Por exemplo, o espaço conceitual da DTC, quando a justificação é entendida de uma forma menos confiabilista do que deontológica, difere do espaço conceitual de uma análise confiabilista simples: crença verdadeira confiável (cf. 
Dawson, 1981, p. 316). Para perceber a diferença dos espaços ocupados, basta ter em atenção que a primeira análise impõe requisitos internalistas (por exemplo, que o agente tenha acesso consciente aos justificantes da suas crença), enquanto a última não.

Propomos agora um exercício. Suponha-se que deseja escalar o K2 (da cordilheira dos Himalaias). Se o tentar fazer em determinadas circunstâncias meteorológicas, pessoais, de equipamento, de guias, etc., propícias para uma boa escalada, poderá consegui-la, mas se tentar em outras circunstâncias em que essas condições não estão reunidas, então, a não ser por um mero acaso, não conseguirá. Isso é uma trivialidade aceita por uma larga maioria de pessoas que emprega o seu bom senso para avaliar problemas práticos que se lhe deparam e para agir corretamente em conformidade com essa avaliação. Se o leitor não está convencido pelo cenário por nós escolhido, suponha que se propõe atravessar o Canal da Mancha a nado. Novamente, se um conjunto de condições são reunidas, por exemplo, a temperatura da água, a corrente, o equipamento do nadador, e por aí em diante, então é provável que consiga fazer a travessia, mas se as circunstâncias forem diferentes, digamos, ligeiramente abaixo das suficientes, então é provável que não a consiga realizar. Por que razão não estaríamos então dispostos a conceder que algo muito semelhante acontece quando nos referimos não a performances práticas bem-sucedidas, como escaladas e travessias, mas a performances intelectuais e cognitivas? Não é o conhecimento também o resultado bem-sucedido de uma performance, tal como escaladas e travessias bem-sucedidas o são (compare-se com Sosa, 2007, p. 23)? Que boas razões há, pois, para se aceitar que, no caso das escaladas e das travessias, as condições necessárias e suficientes para o sucesso da performance podem variar, mas que para o caso do conhecimento essas condições - epistêmicas e não-epistêmicas - têm de ser invariavelmente as mesmas? Se a analogia correr, acreditamos que nenhuma boa razão se apresenta.

Tf. Assumindo, com base no que dissemos, que a possibilidade de múltiplas análises é viável, passemos agora à forma dessas análises. Uma inspeção da literatura acerca do PG mostra-nos que as análises do conceito de conhecimento podem ser intensionalmente idênticas ou distintas, mas que serão sempre extensionalmente diferentes. As análises podem ser intensionalmente iguais, porque partilham as mesmas designações para as condições que colocam como necessárias e suficientes. Há uma abundância de exemplos, especialmente no que respeita a versões de CVJ. Embora intensionalmente iguais, essas análises ou são extensionalmente redundantes, não tendo por isso 
interesse enquanto variações à análise original, ou são extensionalmente diferentes, uma vez que uma das condições com designação partilhada, geralmente a condição de justificação ou a condição de garantia, visa satisfazer diferentes desideratos epistêmicos, não epistêmicos e téoricos. Por outro lado, existem também muitas análises intensional e extensionalmente diferentes. São intensionalmente diferentes porque estabelecem diferentes condições e respectivas designações, e são extensionalmente distintas porque essas condições visam satisfazer diferentes desideratos epistêmicos, não-epistêmicos e teóricos. Exemplos abundam, alguns dos quais já referenciados neste ensaio, pelo que a eles não voltaremos.

Tql. Na acepção tradicional, de raiz platônica, as análises são verdadeiras ou falsas, são não circulares ou circulares, são informativas ou não informativas. Viu-se acima que as análises do conceito de conhecimento ou são falsas ou são viciosamente circulares ou são nãoinformativas (ou todas). Concentremo-nos agora no principal problema, o da falsidade. As análises são falsas porque a bicondicional "S sabe que $p$ se, e só se, $\mathrm{S}$ tem uma $\mathrm{CV}+x$ " é falsa para qualquer valor de $x$. Alegadamente, qualquer instância particular desta bicondicional será falsa, porque $C V+x$ não é necessário, suficiente, ou necessário e suficiente para $\mathrm{S}$ saber que $p$.

Trataremos do problema da suficiência mais adiante. Quanto ao problema da necessidade, importa relembrar o que é geralmente reclamado: para determinados (não todos) valores de $\mathrm{x}, \mathrm{CV}+$ (valor de $x$ ) não é necessário para $\mathrm{S}$ saber que $p$, logo, conhecimento $\neq$ de $\mathrm{CV}+$ (valor de $\mathrm{x}$ ). Mas, qual é o sentido de necessidade em jogo aqui? $\mathrm{O}$ que os contraexemplos à necessidade de determinadas instâncias de $\mathrm{CV}+$ (valor de $\mathrm{x}$ ) mostram é que há pelo menos um caso (geralmente representativo de um conjunto de casos) em que CV+(valor de $x$ ) - ou simplesmente (valor de $\mathrm{x}$ ), uma vez que CV parece ser sempre necessário - não é necessário do ponto de vista lógico para S saber que $p$. Mas, que dizer acerca dos outros casos em que essa necessidade é manifesta? É presumível que muitos casos de conhecimento dispensem justificação concebida internalisticamente, mas será que todos dispensam? Estamos em crer que não: o conhecimento por introspecção parece demandar acesso consciente aos justificantes, por exemplo, de crenças acerca dos meus próprios estados mentais, logo, é justificação concebida internalisticamente. Se isso estiver correto, há um sentido extralógico de necessidade em jogo na expressão " $x$ é necessário para $\mathrm{S}$ saber que $p$ " segundo o qual $\mathrm{CV}+($ valor de $x$ ) é necessário para $\mathrm{S}$ saber que $p$ em determinadas circunstâncias, tempos e vertentes de conhecimento 
proposicional, mesmo considerando que há exceções a essa necessidade. Vamos, pois, apelidar essa necessidade de epistêmica, por contraste com necessidade lógica. A história do PG e a discussão em torno da alegadamente única e verdadeira análise do conceito de conhecimento mostra-nos que há um conjunto alargado de condições epistemicamente necessárias para o conhecimento que não são logicamente necessárias.

Se essa avaliação estiver em ordem, há que ter em conta duas possíveis variantes de uma mesma análise. Por um lado, a análise em sentido estrito, a qual estabelece condições logicamente desnecessárias para S saber que $p$, por outro, a análise em sentido lato, que estabelece condições epistemicamente necessárias para $\mathrm{S}$ saber que $p$. Análises que incluem condições epistemicamente necessárias são válidas do ponto de vista epistêmico, embora falsas. São elucidações do fenômeno do conhecimento que têm um formato de análise extensionalmente incompleta do seu conceito. Como veremos de seguida, a falsidade dessas análises é irrelevante para o propósito de definir o conhecimento, uma vez que é o conjunto de análises válidas que gera e preenche o espaço conceitual da noção de conhecimento, e não uma qualquer análise em sentido lógico.

Talvez o leitor possa compreender melhor a metafísica inerente à nossa proposta, caso pense que o referido espaço não é unidimensional - contendo apenas uma única dimensão de condições -, tal como classicamente postulado, mas sim multidimensional, a saber, contendo uma multiplicidade de dimensões. Cada dimensão é uma análise válida, no sentido descrito por nós, uma dimensão que contribui para preencher um espaço conceitual mais vasto. Se nos for permitido prosseguir com essa imagética, diremos que esse espaço total é um amálgama desse conjunto de dimensões e respectivo espaço conceitual por elas preenchido. Assim, sugerimos nós, a extensão do conceito de conhecimento é transversal a todas essas dimensões. O espaço conceitual da noção de conhecimento é, portanto, uno mas multidimensional, porque multicondicional. Se a nossa perspectiva teórica desse espaço nos revelar essa multidimensionalidade, o que veremos são espaços conceituais autônomos sequencialmente dispostos. Quando a perspectiva teórica é unidimensional, porque focada em uma única análise que indicia um conjunto inflexível de condições, como no caso da DTC, esse espaço apresenta-se estático, rígido e inacabado. O PG e outros problemas mostram justamente contraexemplos à pretensão de completude desse espaço circunscrito a uma única dimensão. Apesar de necessário para o espaço total multidimensional, esse espaço unidimensional referente a uma única análise não pode ser suficiente para preencher essa totalidade. 
Q-me. A suposição de que uma análise do conceito de conhecimento é falsa, ou circular, ou não informativa, depende sempre de um préconceito de conhecimento. Por sua vez, esse pré-conceito depende de intuições acerca do modo apropriado como aprendemos a realidade, de como chegamos à verdade de forma adequada, do que devemos e não devemos acreditar, etc. Ora, essas intuições aparecem em múltiplas análises epistemicamente válidas, como, por exemplo, a DTC ou análises que pressupõem uma relação causal entre fatos e crenças, etc. (cada qual preenchendo uma das dimensões de que falávamos acima). O espaço conceitual relativo ao pré-conceito de conhecimento usado para mostrar que qualquer tentativa de análise lógica do conceito de conhecimento falha é portanto gerado e preenchido por uma variedade de análises epistemicamente válidas, tal como as definimos acima. Não se pode, pois, partir de um pré-conceito de conhecimento para avaliar o que é necessário e suficiente para haver conhecimento, assim circunscrevendo o espaço conceitual relativo à noção de conhecimento, sem se dar primazia às análises epistemicamente válidas que formam esse espaço conceitual.

O que propomos é, pois, uma minirrevolução coperniciana. Em vez de admitirmos a existência de um espaço conceitual rígido e préestabelecido relativo à noção de conhecimento, o qual alegadamente serve para avaliar se uma determinada análise o satisfaz - algo que se revela impossível, uma vez que qualquer análise preenche um espaço conceitual que não cobre todo o espaço conceitual relativo à noção de conhecimento -, considere-se a possibilidade $(\alpha)$ de haver um conjunto vasto de análises válidas (tal com definimos acima) que em conjunto vai gerando, preenchendo e moldando esse espaço conceitual. Se $\alpha$ estiver em ordem, as margens desse espaço alteram-se em função do que determinados conjuntos de circunstâncias e tempos impõem como necessário e suficiente para satisfazer nessas circunstâncias as nossas intuições acerca da noção de conhecimento. Trata-se de conjuntos como \{crença que $p$, justificação da crença que $p$, verdade que $p$, não acidentalidade da crença que $p$, aptidão cognitiva do agente $\}$ ou \{crença que $p$, verdade que $p$, ligação causal entre $p$ e a crença de que $p$, não acidentalidade da crença que $p$ e evidência não anulável de que $p\}$, etc.

E se $\alpha$ estiver em ordem, a exigência de suficiência da análise do conceito de conhecimento adquire novos contornos, pois, como vimos, temos em bom rigor de deixar cair o desiderato de encontrar uma análise lógica que descreva invariavelmente as condições necessárias e suficientes para $\mathrm{S}$ saber que $p$. Assim é porque qualquer análise é logicamente falsificável. E assim é porque não existe uma fronteira imutável para o espaço conceitual relativo à noção de conhecimento. Ora, se essa fronteira 
é variável, particularmente em função de circunstâncias e de tempos, a única definição possível para o conhecimento tem de conter uma variável que possa dar conta das mutações desse espaço conceitual e das suas fronteiras. Dito de outro modo, a suficiência é variável em função das condições necessárias em determinadas circunstâncias e tempos, a limite, em função das análises válidas em determinadas circunstâncias e em determinados tempos.

Vimos que o formato convencional de uma definição do conhecimento é "conhecimento é CV+x". Nessa fórmula, "CV" toma o lugar de duas constantes, crença e verdade, as quais são condições que, por serem consensuais e bastante plausíveis, têm um caráter de permanência no que toca a circunscrever o espaço conceitual relativo à noção de conhecimento. Por seu turno, a cópula "é" indica presumivelmente uma identidade entre o conhecimento e o seu espaço conceitual, por um lado, e crença verdadeira com determinadas propriedades e o seu espaço conceitual, por outro. Por equação simples, de "conhecimento $=\mathrm{CV}+\mathrm{x}$ " podemos derivar "conhecimento- $x=C V$ ". Ou seja, "subtraindo" $x$ do espaço conceitual do conhecimento, obtemos o espaço conceitual relativo à crença verdadeira simpliciter. Se, como defendemos, o espaço conceitual relativo à noção de conhecimento é flexível, segue-se que $x$ deverá assumir diferentes valores consoante as circunstâncias e os tempos de avaliação de "S sabe que $p$ ".

Se o que altera as fronteiras do espaço conceptual relativo à noção de conhecimento é o "valor" que $x$ assume em determinadas circunstâncias e tempos de avaliação de "S sabe que p", e se não é possível fixar um valor incircunstancial e intemporal para $x$, por que não, pois, supor que a melhor definição (que não pode ser uma análise em sentido estrito) do conhecimento é justamente a que dispõe no definiens, além das condições consensuais de crença e verdade, um marcador de posição, que pode ter a forma de uma letra esquemática ou de um termo de arte, e que adquire valores em função do necessário e suficiente para haver conhecimento? Se isso for autorizado, podemos talvez cunhar um termo de arte que possa ocupar o lugar do referido marcador de posição, com o propósito de se obter uma definição mais intuitiva e, por conseguinte, mais de acordo com o senso comum. Segundo nos parece, esse termo deve retratar o melhor possível o vínculo suficientemente forte e indissociável entre crença e verdade que a satisfação de determinadas condições permite, deixando, no entanto, espaço para a falibilidade própria dos empreendimentos epistêmicos dos seres humanos. Esse termo é, a nosso ver, "garantia epistêmica". O conhecimento é pois, nesse sentido nominal da definição, crença verdadeira epistemicamente garantida. 
Por mais não convencional e bizarra que pareça ao leitor, esta parece-nos a única solução possível para o PG. Com efeito, é a única que consegue explicar por que razão não há nenhuma análise que forneça as condições necessárias e suficientes para o conhecimento, explicando de caminho as reais razões para essa falha. Também é a única que acomoda as nossas intuições acerca da necessidade de satisfação de múltiplas condições para $\mathrm{S}$ saber que $p$, logo, a de que há múltiplas análises válidas, apesar de falsas. Além disso, a nossa solução acaba com o dogma filosófico de que o conceito de conhecimento é monolítico e invariável, uma vez que recusa que o espaço conceitual que forma a noção de conhecimento tenha fronteiras imutáveis. Por fim, explica por que razão muitas das propostas de análise de "Sabe que p", principalmente as pós-Gettier, apresentam afinal o copo meio cheio, e não, como tantas vezes admitido, meio ou completamente vazio.

Essa teoria acomoda a maioria dos desideratos expostos na seção 0 e deixa espaço para a compatibilidade das HipC2 e HipC3, as quais estão de acordo com muitos insights acerca do conhecimento. Infelizmente, todas as teorias têm problemas. A nossa não é certamente exceção. $O$ leitor mais perspicaz já tem por essa altura uma objeção forte: a nossa definição é ad-hoc, o que viola o requisito (1) (ver seção 0).

Pensamos que a objeção está parcialmente certa. Dizemos parcialmente, porque a estipulação ocorre apenas em um primeiro nível de definição, mas não nos níveis subalternos, nos quais surgem condições descritivas e normativas que têm por base o trabalho epistemológico de muitos filósofos e refletem, embora não exaustivamente, os programas de investigação que conduziram à sua aceitação generalizada enquanto condições necessárias para S saber que $p$. Essas investigações, com seus sucessos e falhanços, suas virtudes e seus defeitos, fazem-nos pensar que a tarefa de elucidar a noção de conhecimento e de tentar resolver o PG passa por admitir um sistema multidimensional de condições. Se o leitor não concorda com essa disposição teórica multidimensional com uma variável no topo, permitimo-nos chamar-lhe a atenção para o atual estado da discussão científica acerca da constituição do universo. Segundo alguns conceituados cosmólogos, há boa evidência para a existência de matéria e energia negras, mas ninguém sabe o que são exatamente. As expressões "matéria negra" e "energia negra" são definições construídas, estipuladas, aceitas em regra, para dar conta de entidades, substâncias e forças que explicam a melhor evidência científica disponível (observacional e matemática). Por que razão haveria de ser diferente com a noção de conhecimento no interior da epistemologia? 
L. E. Rodrigues - Uma solução não convencional ...

\section{Referências}

AUDI, R. Epistemology - A Contemporary Introduction to the Theory of Knowledge. Oxford: Routledge, ${ }^{3} 2011$. . The Structure of Justification. New York: Cambridge University Press, 1993.

BEANEY, M. "Conceptions of Analysis in the Early Analytic and Phenomenological Traditions: Some Comparisons and Relationships". In: BEANEY, M. (org.). The Analytic Turn: Analysis in Early Analytic Philosophy. New York: Routledge, 2007.

BONJOUR, L.; SOSA, E. Epistemic Justification: Internalism vs Externalism, Foundations vs Virtues. New York: Blackwell, 2003.

CHISHOLM, R. Theory of Knowledge. Englewood Cliffs: Prentice Hall, 1966.

DANCY, J. Epistemologia contemporânea. Trad. Artur Morão. Lisboa: Edições 70, 1985. DAWSON, G. "Justified True belief is Knowledge". In: The Philosophical Quarterly, 31 (1981), p. 315-329.

FLORIDI, L. "On the Logical Unsolvability of the Gettier Problem". In: Synthese, 142 (2004), p. 61-79.

GETTIER, E. “Is Justified True Belief Knowledge?”. In: Analysis, 23 (1963), p. 121-123.

GOLDMAN, A. "A Causal Theory of Knowing". In: The Journal of Philosophy, 64 (1967), p. 357-372.

. "Discrimination and Perceptual Knowledge". In: The Journal of Philosophy, 73 (1976): 73, p. 771-791.

GRECO, J. "Knowledge and Success from Ability". In: Philosophical Studies, 142 (2009), p. 17-26.

GUPTA, A. "Definitions". In: ZALTA, E. (ed.). The Stanford Encyclopedia of Philosophy, 2009, <http://plato.stanford.edu/archives/spr2009/entries/definitions >.

HADDOCK, A.; MILLAR, A.; PRITCHARD, D. The Nature and Value of Knowledge: Three Investigations. Oxford: Oxford University Press, 2010.

HETHERINGTON, S. "Knowing Failably". In: The Journal of Philosophy, 96 (1999): 11, p. 565-587.

. "The Gettier-illusion: Gettier-partialism and Infallibilism". In: Synthese (online) DOI 10.1007/s11229-011-9924-6, (2011).

KLEIN, P. "A Proposed Definition of Propositional Knowledge". In: The Journal of Philosophy, 68 (1971): 16, p. 471-482.

LACKEY, J. “Knowledge and Credit”. In: Philosophical Studies, 142 (2009), p. 27-42.

. "Why we Don't Deserve Credit for Everything we Know". In: Synthese, 158 $\overline{(2007)}$, p. 345-361.

LEHRER, K.; PAXSON, T. "Knowledge: Undefeated Justified True Belief". In: The Journal of Philosophy, 66 (1969), p. 225-237.

LYCAN, W. "On the Gettier Problem Problem". In: HETHERINGTON, S. (org.). Epistemology Futures. Oxford: OUP, 2006, Chapter 9.

LYCAN, W.; MCCALL, D. "The Catastrophe of Defeat". In: Philosophical Studies, 28 (1973), p. 147-150. 
L. E. Rodrigues - Uma solução não convencional ...

NOZICK, R. Philosophical Explanations. Library of Congress, 1981.

PAILTHORP, C. "Knowledge as Justified, True Belief". In: The Review of Metaphysics, 23 (1969): 1, p. 25-47.

PLANTINGA, A. "Analyses and Defeaters". In: Philosophy and Phenomenological Research, 55 (1995): 2, p. 427-464.

. Warrant The Current Debate. Oxford: Oxford University Press, 1993.

PRITCHARD, D. "Achievements, Luck and Value". In: Think, 25 (2010), p. 1-12.

. Epistemic Luck. Oxford: Oxford University Press, 2005.

p. 106-130.

. "Virtue Epistemology and Epistemic Luck". In: Metaphilosophy, 34 (2003),

RADFORD, C. “Knowledge - By Examples". In: Analysis, 27 (1970), p. 1-11.

SARTWELL, C. "Knowledge Is Merely True Belief". In: American Philosophical Quarterly, 28 (1991):2.

SHOPE, K. The Analysis of Knowing. A Decade of Research. Princeton: Princeton University Press, 1983.

SOSA, E. A Virtue Epistemology: Apt Belief and Reflective Knowledge. Oxford: Oxford University Press, 2007.

. "How to Defeat Opposition to Moore". In: Noûs, 33 (1999), p. 141-153.

$\overline{\text { p. 59-66. }}$

. "Two Conceptions of Knowledge". In: The Journal of Philosophy, 67 (1970): 3,

STANLEY, J. Knowledge and Practical Interests. New York-Oxford: Oxford University Press, 2005.

STEUP, M. "Justification". In: Contemporary Debates in Epistemology. Oxford: Blackwell, 2005, p. 251-256.

TURRI, J. (forthcoming) “Gettier Wake”. In: HETHERINGTON, S. (ed.). Epistemology: The Key Thinkers. Cambridge: Cambridge University Press, 2012, p. 214-229.

. “Is Knowledge Justified True Belief?”. In: Synthese, 184 (2012), p. 247-259.

"Manifest Failure: The Gettier Problem Solved". In: Philosophers Imprint, 11

$\overline{(2011):} 8$ (on-line - sem paginação).

UNGER, P. "An Analysis of Factual Knowledge". In: The Journal of Philosophy, 6 (1968), p. 157-170.

WEATHERSON, B. "What Good Are Counterexamples". In: Philosophical Studies, 115 (2003), p. 1-31.

WILLIAMSON, T. Knowledge and its Limits. Oxford: Oxford University Press, 2000.

ZAGZEBSKY, L. "The Inescapability of Gettier Problems". In: The Philosophical Quarterly, 44 (1993): 174, p. 65-73.

. "What is Knowledge?". In: GRECO, John; SOSA, Ernest (eds.). The Blackwell Guide to Epistemology. Malden, MA: Blackwell, 1999, p. 92-116. 